\title{
A 9-10.6 GHz MICROSTRIP ANTENNA - UWB LOW NOISE AMPLIFIER WITH DIFFERENTIAL NOISE CANCELING TECHNIQUE FOR IOT
}

\section{APPLICATIONS}

\author{
Dalia Elsheakh $^{1,2}$, Heba Shawkey ${ }^{1}$, Sherif Saleh ${ }^{1}$ \\ ${ }^{1}$ Electronics Research Institute, El Bohous St., Dokki, Giza, Egypt \\ ${ }^{2}$ Hawaii Center for Advanced Communication, Honolulu, Hawaii, USA
}

The paper is received on May 15, 2019

Abstract. An ultra wide band (UWB) receiver front-end operates at the UWB frequency range, starting from $9 \mathrm{GHz}-10.6 \mathrm{GHz}$ is proposed in this paper. The proposed system consists of an off-chip microstrip antenna and CMOS differential low noise amplifier with a differential noise canceling (DNC) technique. The proposed antenna is trapezoidal dipole shaped with balun and printed on a low-cost FR4 substrate with dimensions $10 \times 10 \times 0.8 \mathrm{~mm}^{3}$. The balun circuit integrated with the ground antenna to improve the antenna impedance matching. Full-wave EM solver HFSS (High Frequency Structure Simulator) is used for modeling the proposed antenna. The CMOS LNA is designed using UMC $0.13 \mu \mathrm{m}$ CMOS process, and exhibits a flat gain of $19 \mathrm{~dB}$, maximum noise figure of $2.9 \mathrm{~dB}, 1 \mathrm{~dB}$ compression point $-16 \mathrm{dBm}$, 3rd order intercept point (IIP3) -10dBm, and DC power consumption of $2.8 \mathrm{~mW}$ at $1.2 \mathrm{~V}$ power supply. Applying the noise canceling stage, the NF is reduced by $50 \%$ to be $2.75 \mathrm{~dB}$ while the power consumption is increased to be $2.9 \mathrm{~mW}$.

Keywords: ultra-wideband (UWB), low noise amplifier (LNA), differential noise canceling, low power, low noise figure.

\section{Introduction}

Recently, rapidly progress are made in ultra-wideband (UWB) applications with high data rate communications in short distances with low fabrication cost as internet of things (IoT) [1]. IoT connects billions of objects to form a huge network for communications and perform smart actions. There aren't any standard definitions for IoT 
[2]. Various definitions are listed as IoT allows things and people to be connected anywhere, and are widely used for sensing applications, security purposes and high data rate $5 \mathrm{G}$ communications since it enables robust wireless systems in dense multipath scenarios [3]. In this paper, a complete UWB receiver for IoT applications is proposed. Wide band has ability for deep wall penetration as well as resolution of sub-nanosecond delays in centimeter-level distance resolutions. Added to this is an improvement on the timing resolution compared to conventional narrowband signals. In addition to broadband gain and input matching requirements, the broadband standard also poses a tight specification on the band switching time, thus precluding the direct synthesis of frequencies by phase locking. An approach suggested for this task incorporates a single phase-locked loop (PLL) and wideband mixer to generate different frequencies that are present at all times and could simply selected as the local oscillator (LO) signal [4]. Compact low-power consumption antennas that can be easily embedded within the system are considered essential for portable IoT devices [5].

UWB antennas used planar microwave circuitry have generated attractive radiating structures with high gain, low weight, reliability, ease of manufacturing and integration such as the Vivaldi antennas and the tapered slot antenna. UWB has many definitions as IEEE (the operating bandwidth greater than $20 \%$ antennas [1]) or as FCC (released in 2002 that the UWB protocol that covers the frequency ranges from 3.1-10.6 GHz). UWB planar microwave circuitry have generated attractive radiating structures with high gain, low weight, reliability, ease of manufacturing and integration such as the Vivaldi antennas [6-7], and the tapered slot antenna [8-9] and planar log-periodic dipole (LPDA) [10-11].

In this paper a complete wideband receiver- front end operates in the frequency range $9-10.6 \mathrm{GHz}$ is proposed. Fig. 1 shows the block diagram for the proposed receiver, which consists of the off-chip microstrip antenna, a balun and on-chip CMOS low noise amplifier (LNA). The LNA is implemented using UMC $130 \mathrm{~nm}$ CMOS technology with a simple noise canceling technique. 


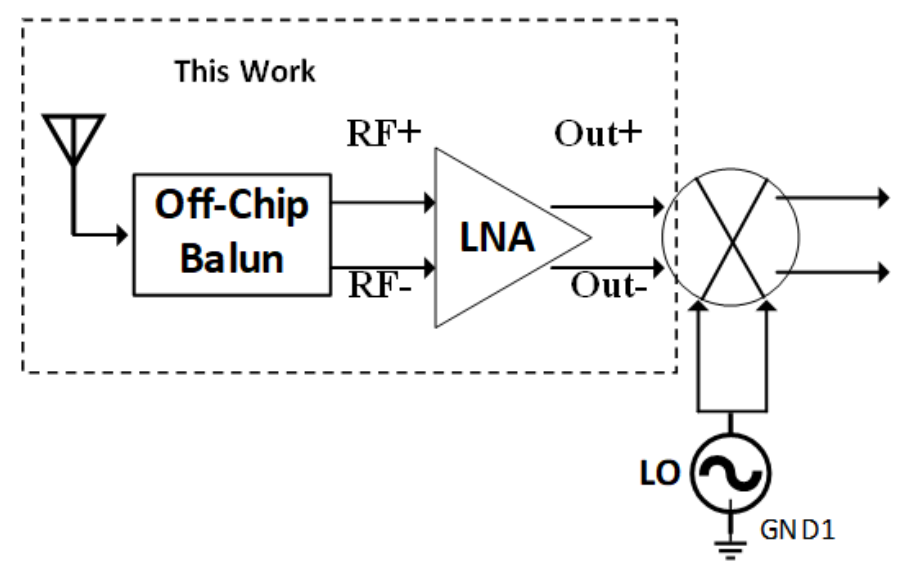

Fig. 1 Block diagram of the propose UWB receiver.

The paper is organized as follows; section II describes the design and analysis of the proposed broadband antenna in terms of reflection coefficient, antenna impedance, efficiency and antenna gain. Ssection III introduced the UWB low noise amplifier with differential noise canceling (DNC) technique. While section IV shows the system simulation, finally, section VI concludes the proposed work.

\section{Wideband Antenna Design}

In this section a new proposed wide bandwidth antenna is presented which consists of a combined structure of different lengths of printed trapezoidal dipole fed by CPW and balun circuit to improve the impedance matching. The proposed antenna as shown in Fig. 2 has been designed with 3D electromagnetic simulation HFSS ver. 14. The proposed antenna dimensions are $10 \times 10 \times 0.8 \mathrm{~mm}^{3}$ when printed on a FR4 dielectric substrate. The proposed CPW trapezoidal dipole antenna introduces UWB with the multiple resonant properties. Fig. 2 shows the geometry and dimensions of the proposed antenna and the final dimensions are shown in table 1. To improve the antenna bandwidth modified rectangular dipole is used by using two different bases width and etching balun to improve the impedance matching with suitable dimensions is used as shown in Fig.3. These wideband are used for different wireless communications applications and for UWB applications. The antenna is fed by $50-\Omega$ transmission line (TL), which can be easily integrated with other microwave circuits printed on the same substrate. 
The proposed antenna is fabricated by using photolithographic technique and it is measured by using a Rohde \& Schwarz ZVA67 vector network analyzer (50MHz to $67 \mathrm{GHz}$ ). Then the comparison results between simulated and measured of the proposed antenna for both reflection coefficient and antenna impedance real and imaginary are shown in Fig. 3(a). This figure shows that good agreement between measured and simulated results and $50 \Omega$ input impedance with zero imaginary part of the proposed antenna at $7.8 \mathrm{GHz}$ with reflection coefficient $\left|S_{11}\right|=-37 \mathrm{~dB}$ with wideband extend from 7 $\mathrm{GHz}$ to $12 \mathrm{GHz}$ at $-6 \mathrm{~dB}$ reflection coefficient which is wide enough to cover the FCC approved UWB in addition to wireless communications. Fig. 3(b) shows that the antenna gain and radiation efficiency for the proposed antenna. It is very clear that the antenna has suitable gain in the frequency range of operations about $3.5 \mathrm{dBi}$ in average while the antenna radiation efficiency has about $80 \%$.

Table 1. Dimensions of the proposed antenna (dimensions in $\mathrm{mm}$ ).

\begin{tabular}{|c|c|c|c|c|c|}
\hline $\mathbf{W}_{\text {sub }}$ & $\mathbf{L}_{\text {sub }}$ & $\mathbf{W}_{\mathbf{g}}$ & $\mathbf{L}_{\mathbf{g}}$ & $\mathbf{g}$ & $\mathbf{S}$ \\
\hline 10 & 10 & 4.8 & 2.8 & 0.2 & 1.8 \\
\hline $\mathbf{W}_{\mathbf{f}}$ & $\mathbf{d}$ & $\mathbf{L}_{\mathbf{s}}$ & $\mathbf{L}_{\mathbf{f}}$ & $\mathbf{W}_{\mathbf{1}}$ & $\mathbf{W}_{\mathbf{2}}$ \\
\hline 0.77 & 0.9 & 1.75 & 4.9 & 2 & 4.375 \\
\hline
\end{tabular}

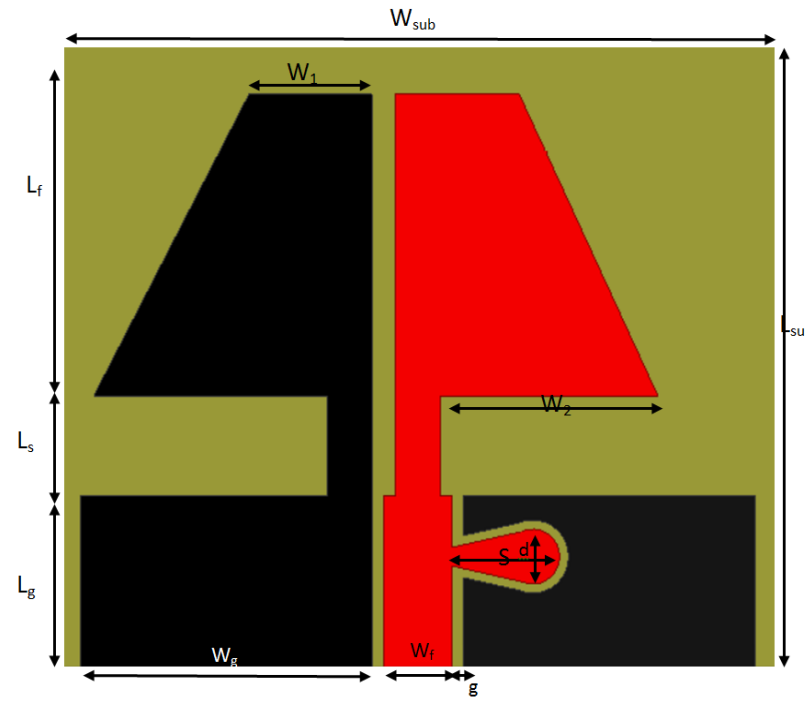

(a)

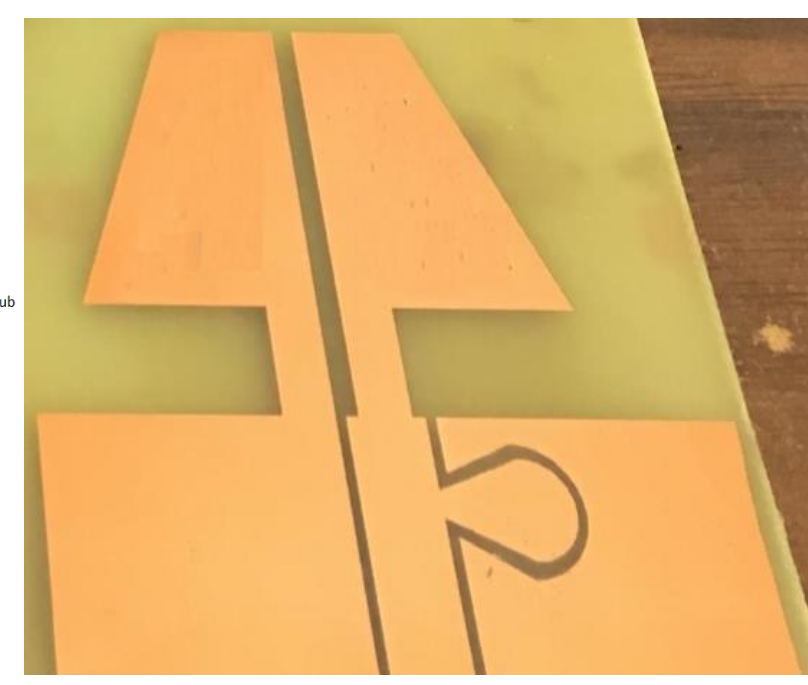

(b)

Fig.2: (a) Layout of the proposed trapezoidal dipole antenna and (b) photo of the fabricated antenna. 


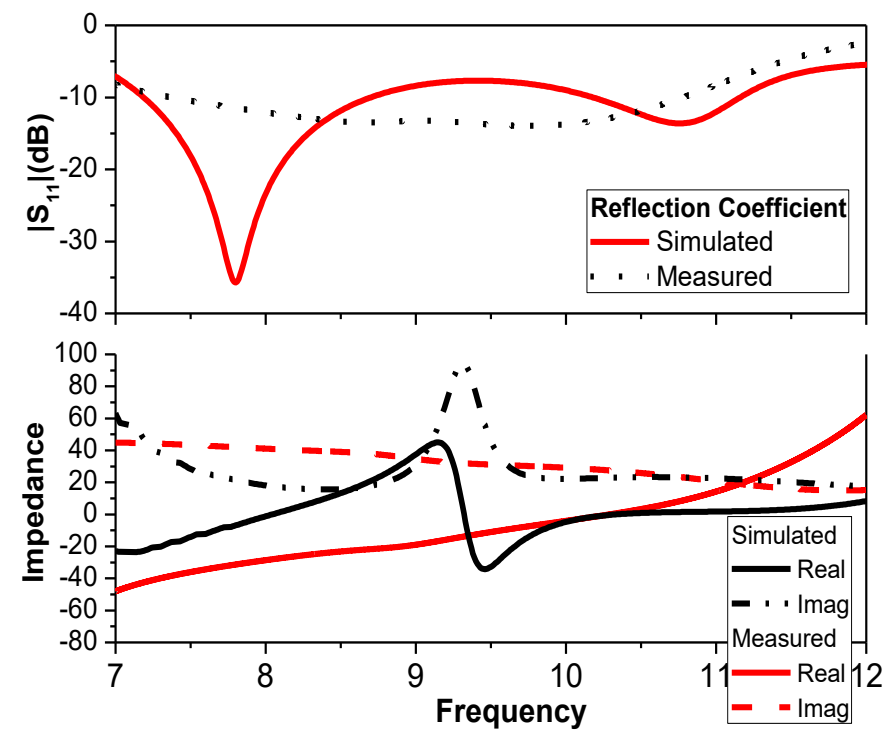

(a)

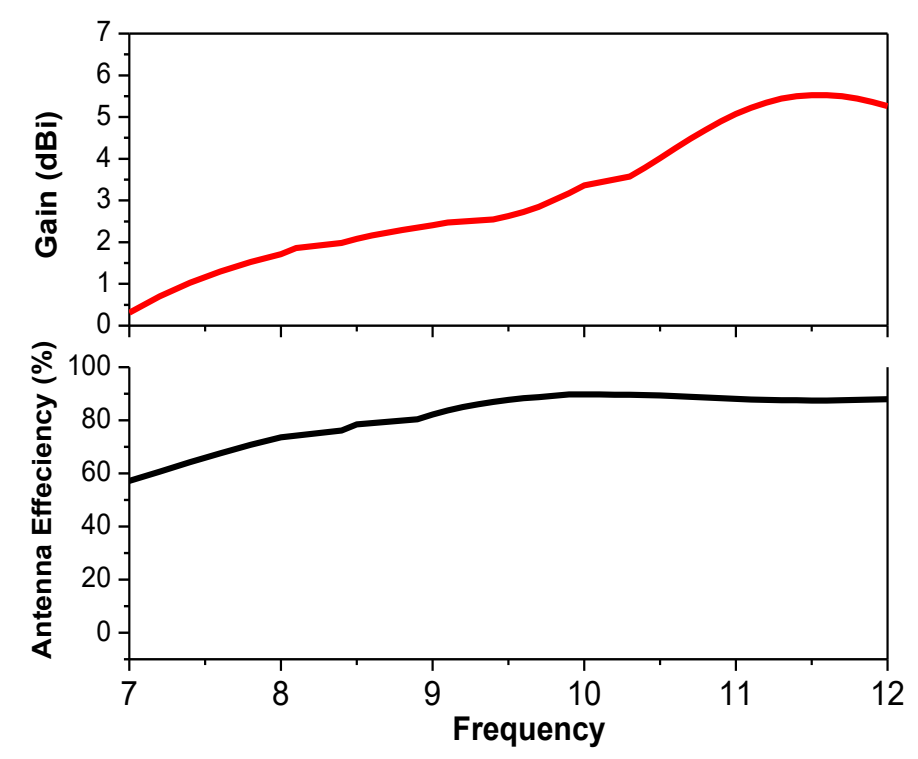

(b)

Fig. 3: (a) Simulated and measured results of the proposed antenna $\left|S_{11}\right|$ with the impedance (real and imaginary) and (b) Simulated gain and radiation efficiency of proposed dipole.

\section{UWB Low Noise Amplifier with Differential Noise Canceling (DNC)}

\section{Technique}

Fig. 4(a) shows a previously reported noise canceling technique [12-15] depends on creating two signals - with two different gain and phase - using 2 amplifiers $\boldsymbol{A}_{\boldsymbol{x}}$ and $\mathbf{A}_{\mathbf{y}}$, the 2 generated signals are subtracted such that the noise is canceled. Fig. 4(b) shows our proposed technique, for a 2-stage differential amplifier with two branches each has a gain $\boldsymbol{A}_{\boldsymbol{1}} \boldsymbol{A}_{2}$. Each branch uses only one noise canceling amplifier $\boldsymbol{A}_{\boldsymbol{n}}$, the output of the noise-canceling amplifier in each branch is added to the input of amplifier $\boldsymbol{A}_{2}$ of other branch, which can be considered as subtraction technique. Fig. 5(a) shows circuit diagram for the proposed LNA. It consists of twostages, a cascade common source common gate (CS-CG) amplifier $-M_{1}$ to $M_{4}$-with inductive load $L_{1}, L_{2}$ and a shunt feedback common source (SF-CS) amplifier $-M_{5}$ and $M_{6^{-}}$to obtain the wideband frequency of operation with an inductive output load $L_{5}, L_{6}$ [12]. Inductive interstage network $-L_{3}, C_{1}$ and $L_{4}, C_{2}$ - is set between the two stages to improve gain bandwidth performance [16]. 

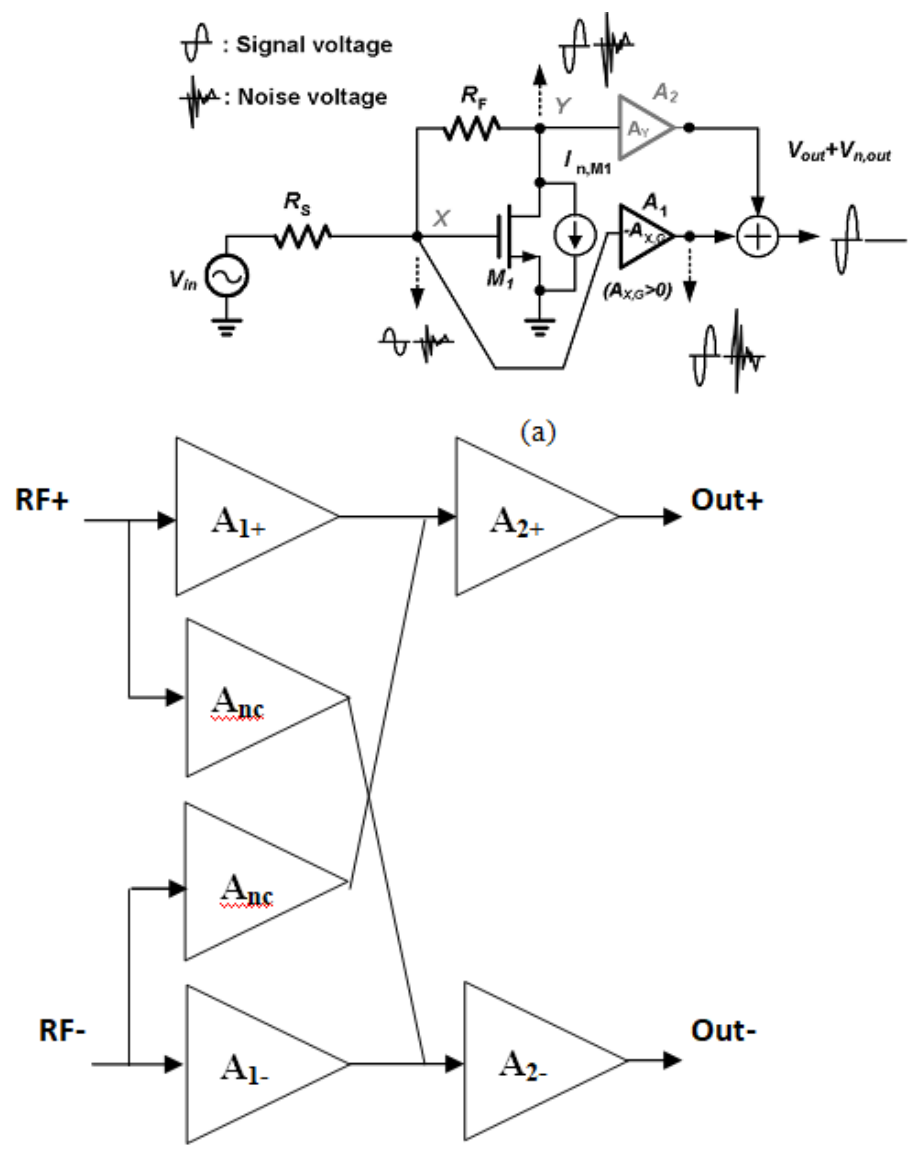

(b)

Fig. 4. (a) Previously reported gain-enhanced noise-canceling technique [16] and (b) Proposed differential noise canceling technique.

$M_{7}$ and $M_{8}$ represent the noise canceling amplifiers with their biasing resistances $R_{b}$. Simulation for the LNA connected to a $50 \Omega$ load terminal with and without noise canceling blocks is shown in Fig.6. Fig.6(a) shows a flat gain with maximum 19dB and $0.5 \mathrm{~dB}$ gain attenuation between maximum and minimum gain in the frequency band 9-10.6 GHz, while Gain NC represents the gain with the noise canceling blocks that improves the flatness of the gain and widens its bandwidth. Fig.6(b) shows that the LNA has $5.5 \mathrm{dBNF}$ at $10 \mathrm{GHz}$, adding the noise canceling blocks reduces NF to $2.75 \mathrm{dBwhich}$ is considered a good improvement compared with other low noise topologies that uses inductors with large area compared with the blocks added. The proposed LNA has a DC power dissipation $2.8 / 2.9 \mathrm{~mW}$ 
without/with noise canceling block. This shows that the proposed noise canceling technique improves the NF by $50 \%$ while power dissipation is increase by $0.1 \mathrm{~mW}$. Besides, the DNC block doesn't contain inductors which leads to negligible area increment and the dimensions of the proposed LNA is listed in Table 2.

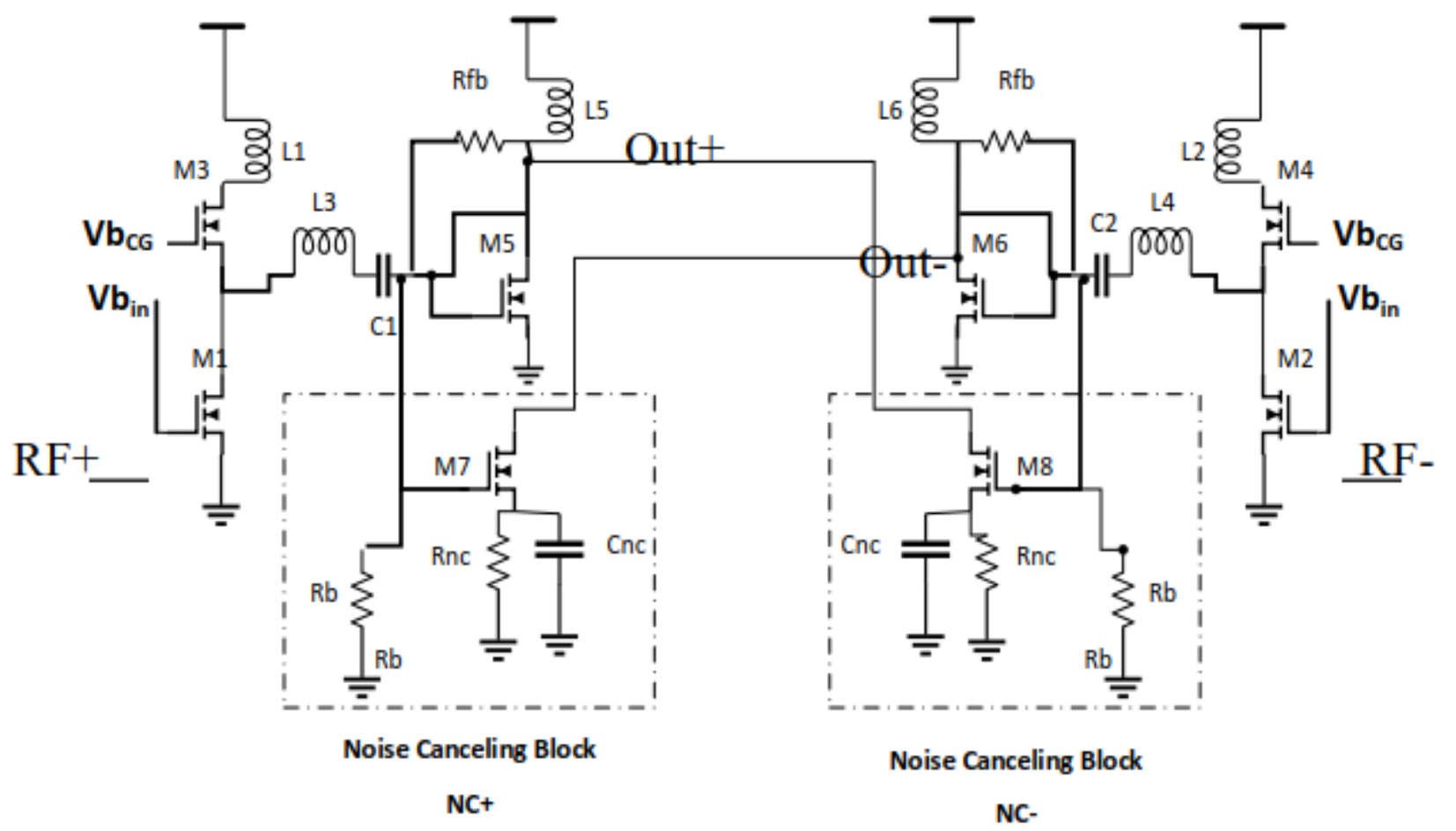

Fig. 5. UWB LNA circuit diagram with proposed differential noise canceling block.

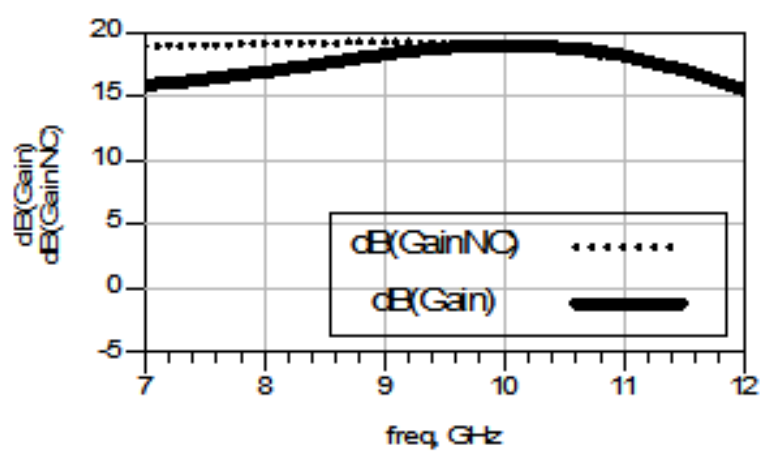

(a)

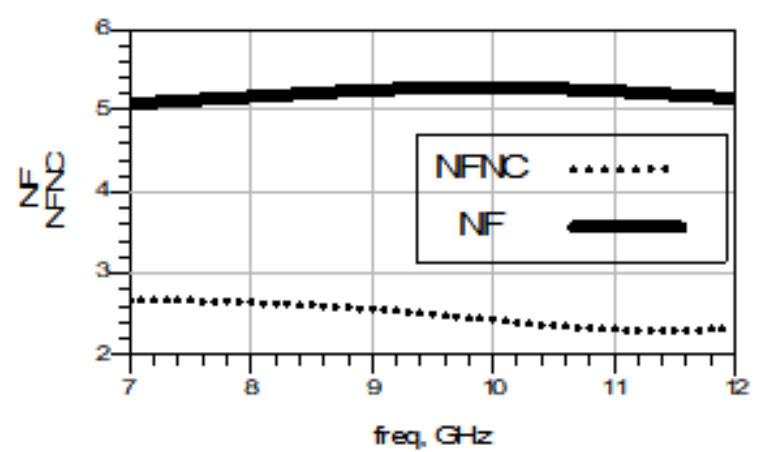

(b)

Fig. 6. LNA Simulation with/without Noise Canceling blocks (a) gain and (b) Noise Figure.

Table 2. Dimensions of the proposed antenna 


\begin{tabular}{|c|c|c|c|c|c|c|c|c|c|c|}
\hline $\begin{array}{c}\mathbf{M}_{\mathbf{1}}-\mathbf{M}_{\mathbf{4}} \\
(\mu \mathrm{m})\end{array}$ & $\begin{array}{c}\mathbf{M}_{\mathbf{5}}-\mathbf{M}_{\mathbf{6}} \\
(\mu \mathrm{m})\end{array}$ & $\begin{array}{c}\mathbf{M}_{\mathbf{7}}-\mathbf{M}_{\mathbf{8}} \\
(\mu \mathrm{m})\end{array}$ & $\begin{array}{c}\mathbf{L}_{\mathbf{1}}, \mathbf{L}_{\mathbf{2}} \\
(\mathbf{n H})\end{array}$ & $\begin{array}{c}\mathbf{L}_{\mathbf{3}}, \mathbf{L}_{\mathbf{4}} \\
(\mathbf{n H})\end{array}$ & $\begin{array}{c}\mathbf{L}_{\mathbf{5}}, \mathbf{L}_{\mathbf{6}} \\
(\mathbf{n H})\end{array}$ & $\begin{array}{c}\mathbf{C}_{\mathbf{1}}, \mathbf{C}_{\mathbf{2}} \\
(\mathbf{p F})\end{array}$ & $\begin{array}{c}\mathbf{C n c} \\
(\mathbf{p F})\end{array}$ & $\begin{array}{c}\mathbf{R}_{\mathbf{F B}} \\
(\mathbf{\Omega})\end{array}$ & $\begin{array}{c}\mathbf{R}_{\mathbf{n c}} \\
(\mathbf{\Omega})\end{array}$ & $\begin{array}{c}\mathbf{R}_{\mathbf{b}} \\
(\mathbf{\Omega})\end{array}$ \\
\hline $224 / 0.13$ & $115.2 / 0.3$ & 28.8 & 1 & 2.3 & 3 & 0.3 & 0.9 & 200 & 100 & $12 \mathrm{~K}$ \\
\hline
\end{tabular}

\section{System Simulation}

The complete receiver front-end-including antenna S-parameters - is simulated to check the complete system performance. Fig.7 (a) shows flat gain in the band of operation 9-10.6GHz with slight variation compared with LNA gain (Gain NC) shown in Fig 6(a) which shows the perfect matching between the balun and LNA. Fig.7 (b) shows that maximum Noise Figure NF is $3 \mathrm{~dB}$ in the band of operation. The linearity is shown in Fig.7(c) with $1 \mathrm{~dB}$ compression point $-16 \mathrm{dBm}$, 3rd order intercept point (IIP3) -10dBm. Fig.7(d) shows a good matching between antenna and LNA with input reflection coefficient $<-10 \mathrm{~dB}$. Table 3 shows a comparison between the proposed system and other UWB receivers' front -end.

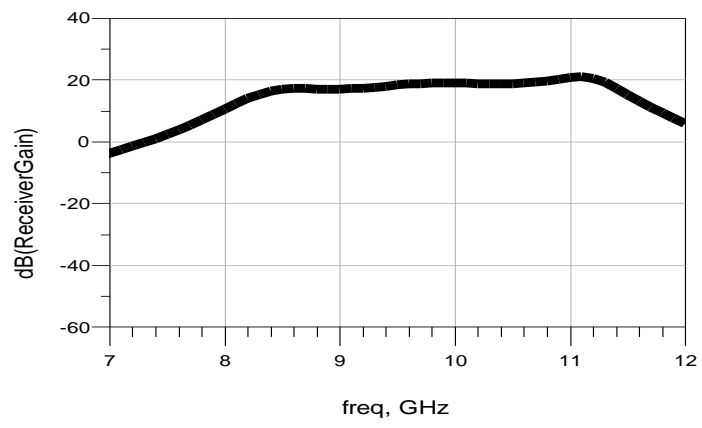

(a)

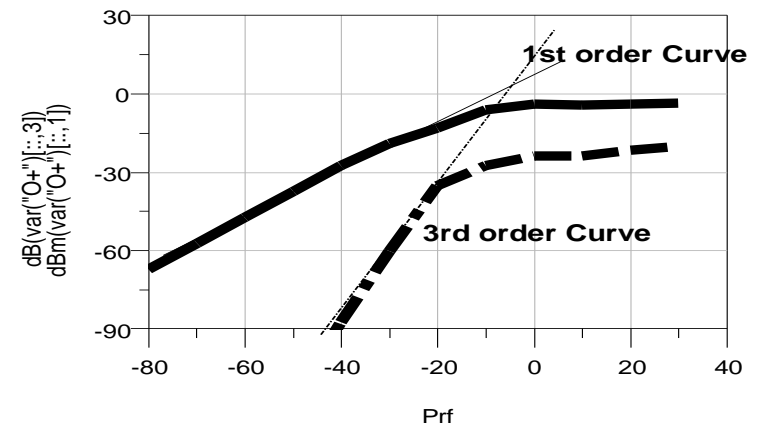

(c)

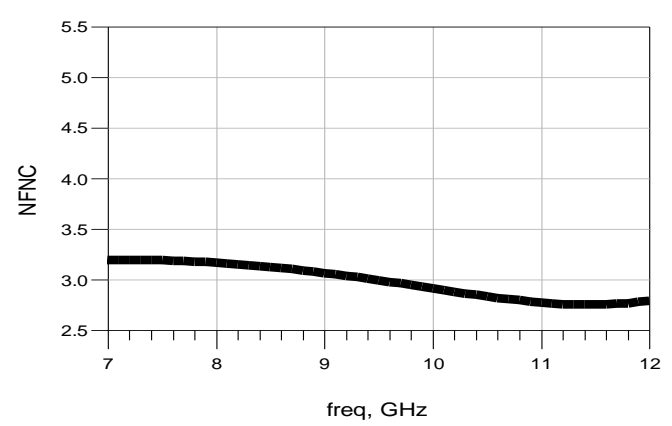

(b)

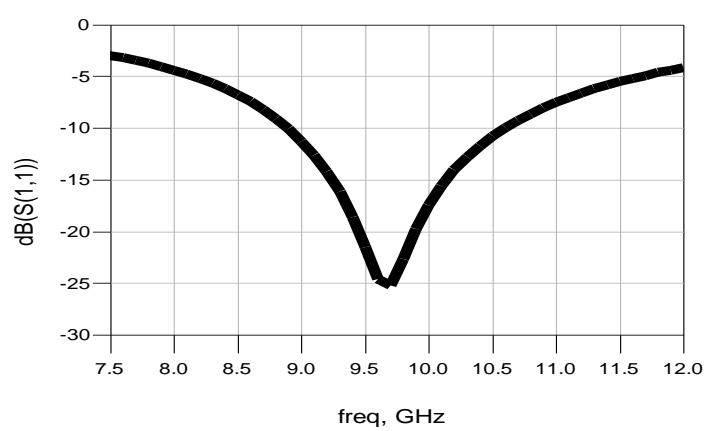

(d)

Fig. 7 Complete receiver front-end simulation Performance (a) gain (b) Noise Figure, (c) linearity and (d) input matching. 
It is clear from the table that the proposed system has very low power dissipation, high gain and low NF compared with other topologies. Although, the IIP3 is low but it could accept for UWB receivers. Moreover, the proposed LNA has limited number of on-chip inductors, which lead to small implementation area. All these specifications make it suitable for low power applications as IoT, WSN and general sensing applications.

Table 3. Performance Comparison with previously reported UWB LNA

\begin{tabular}{|c|c|c|c|c|c|c|}
\hline Ref. & {$[\mathbf{1 6}]$} & {$[\mathbf{1 7}]$} & {$[\mathbf{1 8}]$} & {$[\mathbf{1 9}]$} & {$[\mathbf{2 0}]$} & This work \\
\hline Technology & $0.18 \mu \mathrm{m}$ & $0.09 \mu \mathrm{m}$ & $0.18 \mu \mathrm{m}$ & $0.13 \mu \mathrm{m}$ & $0.18 \mu \mathrm{m}$ & $0.13 \mu \mathrm{m}$ \\
\hline Frequency (GHz) & $3.2-6.3$ & $\begin{array}{c}2.4- \\
10.4\end{array}$ & $3.1-4.9$ & $3-12$ & $3-10$ & $9-10.6$ \\
\hline Gain (dB) & 15 & 9.5 & 14.1 & 13.5 & 13.7 & 19 \\
\hline IIP3 (dBm) & N/A & 13.1 & -6.7 & -7 & -0.2 & -10 \\
\hline Noise Figure (dB) & 0.95 & 4 & 4.29 & 4.3 & 2.2 & 2.9 \\
\hline Supply (V) & 1.8 & 1.2 & 1.8 & 1.2 & 1.8 & 1.2 \\
\hline $\begin{array}{c}\text { Power } \\
\text { Dissipation(mW) }\end{array}$ & 4.7 & 14.8 & 4.5 & 8.5 & 18 & 2.9 \\
\hline
\end{tabular}

\section{Conclusion}

This paper has proposed a low power, low NF UWB receiver front-end. The proposed system consists of an ultra-wideband $\mathrm{CPW}-$ fed trapezoidal dipole shaped antenna and a CMOS LNA. The dipole antenna creates an ultra-wideband extended from $7 \mathrm{GHz}$ to $12 \mathrm{GHz}$. The LNA consists of two stages with Inductive interstage network to increase BW and a noise canceling stage to improve NF with simple MOSFET. The proposed system has a 19dB flat gain in the frequency band 9-10.6 GHz with low NF 2.75dB, low DC power consumption $2.9 \mathrm{~mW}$ which make it suitable for IoT technology and sensing applications.

\section{References}

1. Federal Communication Commission. First report and order-revision of part 15 
of the commission's rules regarding ultra-wideband transmission system. FCC 02 48, 2002. Available at https://transition.fcc.gov/Bureaus/Engineering Technology/Orders/2002/fcc02048. pdf

2. P. Srivatsa, A. Pandhare. Indoor Air Quality: IoT Solution. International Journal of Research in Advent Technology, Special Issue National Conference" NCPCI-2016,2016, pp. 218-220. Available at http://www.ijrat.org/downloads/ncpci2016/ncpci-46.pdf

3. A. Batra et al. Multi-Band OFDM Physical Layer Proposl. IEEE 802.1503/267r5, July, 2003. Available at http://grouper.ieee.org/groups/802/15/pub/2003/Jul03/03268r2P802-15_TG3aMulti-band-CFP-Document.pdf

4. F. Wu, C. Rüdiger, M. R. Yuce. Real-time performance of a self-powered environmental IoT sensor network system. Sensors, 2017, Vol. 17, No. 2, pp. 282. Available at https://www.ncbi.nlm.nih.gov/pmc/articles/PMC5336020/

5. GSM Association."5G Spectrum-Public Policy Position. White paper, Nov. 2016. Available at https://gscoalition.org/cms-data/position-papers/GSC\%205G.pdf

6. D. N. Elsheak, E. A. Abdallah. Compact shape of Vivaldi antenna for water detection by using ground penetrating radar (GPR). Microwave and Optical Technology Letters, 2014, Vol. 56, No.8. Available at https://onlinelibrary. wiley.com/doi/full/10.1002/mop.28451

7. G.K.Pandey, H.Verma, M.K.Meshram. Compact antipodal Vivaldi antenna for UWB applications. Electronics Letters, 2015, Vol. 51, No. 4, pp.308-310. Available at https://ieeexplore.iee.org/document/7042450 
8. CJ Wang, Li SC, Sun TL, Lin CM. A wideband stepped-impedance open-slot antenna with end-fire directional radiation characteristics. AEU - In.t J. Electron Communication, 2013, Vol.67, pp.175-81. Available at https://www.sciencedirect.com/science/article/pii/S1434841112001768

9. F. Zhang, G.-Y.Fang, Y. C., Ji, H.-J. Ju, J-J. Shao. A novel compact double exponentially tapered slot antenna (DETSA) for GPR applications. IEEE Antenna Wireless Propag. Letters, 2011, Vol.10, pp.195-198. Available at http://ieeexplore.ieee.org/stamp/stamp.jsp?tp=\&arnumber=5725158\&isnumber $=5$ $\underline{730210}$

10. W. Mazhar D. Klymyshyn, A. Qureshi. Log periodic slot loaded circular Vivaldi antenna for 5-40 GHz UWB application. Microwave and Optical Technology Letters, 2017, Vol.59, pp. 159-163. Available at https://onlinelibrary.wiley.com/doi/full/10.1002/mop.30252

11. D. M. Elsheakh, E. A. Abdallah. Ultra wideband CPW-fed log periodic dipole antenna (LPDA) for wireless communication applications. Joumal of Electromagnetic Analysis and Applications, 2018, Vol. 10, pp.119-129. Available at

https://www.scirp.org/Journa1/PaperInformation.aspx?PaperID=85767

12. K.-Hou Che, S.-Iuan Liu. Inductorless wideband CMOS low-noise amplifiers using noise-canceling technique. IEEE Transactions on Circuits and Systems-I: Regulated paper, 2012, Vol. 59, No. 2. Available at http://ieeexplore.ieee.org/stamp/stamp.jsp?tp=\&arnumber=5995126\&isnumber=6 $\underline{139305}$

13. X. J. Li1, Y. P. Zhang. CMOS low noise amplifier design for microwave and mm wave applications. Progress In Electromagnetics Research, 2018, Vol. 161, pp.57-85. Available at http://www.jpier.org/PIER/pier161/06.18012410.pdf 
14. S.-K. Wong, F. Kung. Design of 3 to $5 \mathrm{GHz}$ CMOS low noise amplifier for ultra-wideband (UWB) system. Progress in Electromagnetics Research C, 2009, Vol. 9, pp.25-34. Available at http://www.jpier.org/PIERC/pierc09/03.09062202.pdf

15. A. Dorafshan, M. Soleimani. High-gain CMOS low noise amplifier for ultrawideband (UWB) wireless receiver. Progress in Electromagnetics Research $C$, 2009, Vol. 7, pp. 183-191. Available at http://www.jpier.org/PIERC/pierc07/14.08090903.pdf

16. H. Shawkey. A 3.5 - 4.5 GHz Flat Gain UWB LNA. International Journal of Electrical \& Computer Sciences IJECS-IJENS, 2014, Vol. 14, No.6. Available at http://ijens.org/Vol_14_I_06/141506-8383-IJECS-IJENS.pdf

17. Y.e Wang. A 4.7-10.5-GHz Ultra-wideband CMOS LNA using inductive interstage bandwidth enhancement technique. 49th IEEE International Midwest Symposium on Circuits and Systems, MWSCAS 2006. Available at https://ieeexplore.ieee.org/document/4267326

18. M. Ikram Malek, Suman Saini. Improved two stage ultra-wideband CMOS low noise amplifier without band rejection using low noise active inductor. 2015 International Conference on Signal Processing and Communication Engineering Systems, Jan. 2015, India. Available at https://ieeexplore.ieee.org/xpl/mostRecentIssue.jsp?punumber=7052448 http://ieeexplore.iee. $.0 r g /$ stamp/stamp.jsp?tp=\&arnumber $=7058237 \&$ isnumber $=70$ $\underline{58196}$

19. B. Mazhab, J. Mohammad Yavari. A UWB CMOS low-noise amplifier with noise reduction and linearity improvement techniques. Microelectronics Journal, 2015, Vol. 46, pp.198-206. Available at https://www.sciencedirect.com/science/article/abs/pii/S0026269214003565

20. T. Zainal, A. Zulkifli, A. Marzuki, S. A. Zainol Murad. UWB CMOS low noise 
amplifier for mode 1. 2017 IEEE Asia Pacific Conference on Postgraduate Research in Microelectronics and Electronics (Prime Asia). Available at http://ieeexplore.ieee.org/stamp/stamp.jsp?tp=\&arnumber=8280378\&isnumber $=8$ $\underline{280348}$

\section{For citation:}

Dalia Elsheakh, Heba Shawkey, Sherif Saleh. A 9-10.6 GHz Microstrip Antenna - UWB Low Noise Amplifier with differential Noise Canceling technique for IoT applications. Zhurnal Radioelektroniki - Journal of Radio Electronics. 2019. No. 5. Available at http:/jre.cplire.ru/jre/may19/13/text.pdf DOI 10.30898/1684-1719.2019.5.13 